\title{
Use of Tocopherol Extract and Different Nitrite Sources and Starter Cultures in the Production of Organic Botifarra Catalana, a Cooked \\ Cured Sausage
}

\author{
Núria Magrinyà ${ }^{1}$, Ricard Bou ${ }^{1,2 *}$, Núria Rius ${ }^{3}$, Rafael Codony $^{1}$, Francesc Guardiola $^{1}$ \\ ${ }^{1}$ Nutrition and Food Science Department- XaRTA-INSA, Faculty of Pharmacy, \\ University of Barcelona, Av. Joan XXIII s/n, 08028 Barcelona, Spain \\ ${ }^{2}$ Institute of Food Science, Technology and Nutrition (ICTAN-CSIC), Spanish National \\ Research Council, C. Jose Antonio Novais 10, 28040 Madrid, Spain \\ ${ }^{3}$ Department of Health Microbiology and Parasitology, Faculty of Pharmacy, \\ University of Barcelona, Av. Joan XXIII s/n, 08028 Barcelona, Spain
}

Corresponding author: Ricard Bou. Tel.: (+34) 91549 2300; fax: (+34) 91549 3627; email: ricard_bou@ictan.csic.es 


\section{ABSTRACT}

2 This research evaluates the effects of adding a tocopherol mix (200 mg/kg), two nitrite 3 sources (sodium nitrite or a nitrate-rich vegetable concentrate) and the use of 4 Staphylococcus carnosus together with three fermentation types that varied in 5 temperature $\left(12 \mathrm{~h}\right.$ at $4{ }^{\circ} \mathrm{C}$ or $\left.16^{\circ} \mathrm{C}\right)$ on different quality parameters and acceptability of 6 cooked cured sausages after vacuum packing and storage at $4{ }^{\circ} \mathrm{C}$ for 120 days. In the 7 presence of $S$. carnosus, residual nitrate and nitrite levels were reduced. Sausages 8 containing vegetable concentrates and without $S$. carnosus resulted in higher amounts of 9 residual nitrate and lower curing efficiency. The lowest values in redness and 10 acceptability were observed in those sausages without starter cultures. The addition of 11 tocopherols had no effect on oxidative status and susceptibility to oxidation. However, 12 the highest amount of hydroperoxides was related with nitrite decreased formation. 13 Overall, vegetable concentrates can be used as curing agents if fermentation with a 14 nitrate-reducing starter culture is allowed.

16 KEYWORDS: cooked cured meat; organic meat products; nitrate and nitrite reduction;

17 nitrate-reducing starter culture; vegetable concentrate, oxidation 


\section{INTRODUCTION}

21 Fermented meat products have their roots in an age-old tradition and are mainly 22 produced in the Western world (Hammes, 2012). Several types of cured meat products 23 are produced in Spain, some of which are specialties from different regions. In 24 Catalonia (Northeastern Spain), botifarra catalana, a traditional cooked cured sausage, 25 is produced using a manufacturing process similar to that of cooked cured ham. The 26 only curing agent permitted in the production of botifarra catalana is nitrite (European 27 Commission, 2006), which provides the distinctive color of cooked cured meat. Nitrite 28 also acts as an antimicrobial against Clostridium botulinum, prevents oxidation, and 29 gives the sausage its cured flavor (Pegg and Shahidi, 2000). Despite all of these 30 desirable effects, under certain conditions, nitrite can react with amines and amino acids 31 in meat and produce $N$-nitrosamines, which play a role in human carcinogenesis.

32 Therefore, the amount of curing agent that can be added to or contained in the cured 33 product is regulated in Europe (European Commission, 2006) and the US (Sebranek and 34 Bacus, 2007).

35 Consumer's interest in eco-labeled foods continues to grow because they perceive these 36 products to be healthier, tastier and of higher quality, produced with animal welfare in 37 mind and free of additives. In this context, the production of cured organic meat 38 products involves the reduction and/or omission of curing agents (Sebranek and Bacus, 39 2007; European Commission, 2008). However, the application of this reduction and/or 
40 omission without sufficient technological knowledge and modification of processes

41 may result in poor sensory and microbiological quality (Hammes, 2012). As an

42 alternative, vegetables and vegetable concentrates (VC), which have naturally occurring

43 nitrates, have been used to circumvent the addition of curing salts to prevent the loss of

44 the typical sensory characteristics of classical curing. Once added to sausages, nitrate

45 needs to be reduced to nitrite to maximize the potential for introducing natural sources

46 of nitrite into the processed meat (Sebranek and Bacus, 2007).

47 The introduction of starter cultures allowed the meat industry to control the 48 fermentation process to ensure high standards of sensory quality and hygiene while 49 reducing production times and costs. Some starter cultures also ensure that the added 50 nitrate or nitrite is reduced to safe low limits (Hammes, 2012). The most efficient 51 nitrate-reducing organisms are staphylococci and micrococci and these are therefore 52 crucial for meats cured using nitrate sources (Sebranek and Bacus, 2007). Regarding the 53 production of catalana sausages, in a previous study (Magrinya et al., 2012), a 54 combination of two starter cultures (one containing lactic acid bacteria and the other 55 containing Staphylococcus carnosus with intense nitrate reductase activity) was used 56 and the fermentation time (at $16^{\circ} \mathrm{C}$ ) required for nitrate reduction was optimized. 57 However, considering that similar results were obtained for the different fermentation 58 times assayed $(6,12$ or $24 \mathrm{~h})$, it was hypothesized that the progressive cooking used for 59 the catalana sausages, which includes an initial step at $40{ }^{\circ} \mathrm{C}$ for $2 \mathrm{~h}$, was responsible 
60 for the almost complete nitrate reduction. Therefore, it is unclear if the fermentation

61 with these starter cultures at $16{ }^{\circ} \mathrm{C}$ offers a clear advantage compared to other

62 alternative production procedures, resembling more the traditional process, in which the

63 fermentation is carried at lower temperatures without the addition of starter cultures.

64 Lipid oxidation promotes rancidity changes and has also been correlated with meat 65 discoloration (Wood et al., 2008; Parra et al., 2010). Nitrite exerts a relevant 66 antioxidative effect acting by different mechanisms (Pegg and Shahidi, 2000).

67 Therefore, reducing nitrite levels may increase the susceptibility of sausages to 68 oxidation, thereby making it necessary to protect these meat products with antioxidants.

69 Dietary supplementation with tocopherol acetate resulted in the stabilization of the 70 desired color and inhibits lipid oxidation in cooked hams (Dineen et al., 2000). In a 71 previous work, it was found that the addition of a tocopherol extract prevented from 72 oxidation and improved red color of dry-fermented sausages during storage (Magrinya 73 et al., 2009). Botifarra catalana is commonly distributed in retail markets vacuum74 packed and under refrigeration conditions. In this regard, the addition of tocopherol in 75 the formulation of this sausage may prevent oxidation during cooking and/or extend its 76 shelf-life.

77 Therefore, the objective of the present study was to examine the effects of producing organic botifarra catalana using various methods, including the addition of tocopherol 
$80 \mathrm{~h}$ at $16^{\circ} \mathrm{C}$ vs $12 \mathrm{~h}$ at $4^{\circ} \mathrm{C}$ ) with and without the addition of different starter cultures, on

81 various quality parameters.

\section{MATERIAL AND METHODS}

\subsection{Reagents, standards and ingredients}

84 Tocopherol extract (Guardian ${ }^{\mathrm{TM}}$ Toco 50, 50\% mixed tocopherols) was obtained from

85 Danisco (Copenhagen, Denmark). A bioprotective starter culture containing 86 Lactobacillus sakei and Staphylococcus xylosus (B-FM SafePro ${ }^{\mathrm{TM}}$ ), a culture with 87 intense nitrate reductase activity that contains Staphylococcus carnosus (CS-300 88 BactoFerm $\left.{ }^{\circledR}\right)$ and a VC (Natasy CC 227) were obtained from CHR Hansen (Hørsholm, 89 Denmark). Sodium nitrite, used as a pure sodium-nitrite source (99.6\%), was obtained 90 from Merck (Darmstadt, Germany). Sodium ascorbate, dextrose and salt were obtained 91 from Espècies Teixidor (Manresa, Spain). Organic lean back meat and jowl fat were 92 obtained from Embotits Salgot (Aiguafreda, Spain). Ground white pepper was obtained 93 from Gewürzmüller (Korntal-Münchingen, Germany). Tocopherol standards were 94 obtained from Calbiochem (San Diego, CA, USA). All chemicals used were of ACS 95 grade except the solvents used in the induced ferrous oxidation-xylenol orange (FOX) 96 method, the Hornsey method and the tocopherol plus tocotrienol determination, which 97 were of HPLC grade. 
99 Twelve treatments resulted from a $2 \times 3 \times 2$ factorial design (Table 1) aimed at studying

100 the effects of adding a tocopherol extract ( 0 and $200 \mathrm{mg}$ of mixed tocopherols $/ \mathrm{kg}$ of raw

101 mixture), of three different types of fermentation $\left(12 \mathrm{~h}\right.$ at $16{ }^{\circ} \mathrm{C}$ with bioprotective and

102 nitrate-reducing cultures, type $\mathrm{A}$; at $4{ }^{\circ} \mathrm{C}$ with only a nitrate-reducing culture, type $\mathrm{B}$; or,

103 at $4{ }^{\circ} \mathrm{C}$ without starter cultures, type C), and of two different sources of nitrite (pure

104 sodium nitrite or a $\mathrm{VC}$, each providing the equivalent of $70 \mathrm{mg}$ of $\mathrm{NaNO}_{2} / \mathrm{kg}$ raw

105 mixture), on several quality parameters of cooked cured meat. The concentration of

106 nitrite added was below the maximum level of ingoing sodium nitrite allowed in organic

107 meat products in Europe (European Commission, 2008). A previous study that

108 examined different fermentation times at $16{ }^{\circ} \mathrm{C}$ demonstrated that type A yielded

109 botifarra catalana with acceptable quality parameters (Magrinya et al., 2012). Type B

110 was included because the nitrate-reducing culture used is, according to the producer,

111 effective at low temperatures $\left(10^{\circ} \mathrm{C}\right)$, and the progressive cooking procedure, including

112 an initial step at $40{ }^{\circ} \mathrm{C}$ for $2 \mathrm{~h}$, favors its activity (Magrinya et al., 2012). Sausages

113 produced in the different treatments were cooked and thereafter stored at $4{ }^{\circ} \mathrm{C}$ for 0,60

114 or 120 days. The inclusion of storage time as a factor thus resulted in 36 different 115 samples.

\section{2.3. Sausage preparation and sampling}

117 With the exception of some of the factors studied, the sausage formulation and 118 elaboration procedures used in this study are typical of botifarra catalana. A mixture 
consisting of $40.8 \mathrm{~kg}$ of lean back meat plus $4.8 \mathrm{~kg}$ of jowl fat from organic pigs (both

120 bought directly from Embotits Salgot) was used to prepare the ground meat. After 121 homogenization, raw mixture was divided into two batches of $22.8 \mathrm{~kg}$. For 122 microbiological quality control of the meat mixture, $50 \mathrm{~g}$ of each batch was taken 123 aseptically and analyzed as described below. Afterwards, $100 \mathrm{~mL}$ of sunflower oil with 124 or without tocopherol extract was added to each batch. In each batch, the common 125 ingredients (432 g salt, $72 \mathrm{~g}$ white pepper and $72 \mathrm{~g}$ dextrose) were added following 126 dispersal in $300 \mathrm{~mL}$ of cold spring water. Following the addition of these ingredients, 127 each batch was mixed for 90 seconds. To characterize these initial raw mixtures 128 (moisture, crude fat, fatty acid composition, $\mathrm{pH}$, and tocopherol and tocotrienol 129 content), samples from these two mixtures, with and without tocopherol extract, were 130 finely ground (Retsch knife mill, model Grindomix GM200; Haan, Germany) and 131 vacuum packed in high-barrier multilayer bags (Cryovac ${ }^{\circledR}$ BB325; 130 x $180 \mathrm{~mm}$; 132 permeability to oxygen, $25 \mathrm{~cm}^{3} \cdot \mathrm{m}^{-2} \cdot$ day $^{-1} \cdot \operatorname{bar}^{-1}$ at $23{ }^{\circ} \mathrm{C}$ and $0 \% \mathrm{RH}$; approximately $20 \mathrm{~g}$ 133 of meat $/ \mathrm{bag}$ ) and stored at $-25^{\circ} \mathrm{C}$ until analysis.

134 Each batch was further divided in three, resulting in six different batches of $7.8 \mathrm{~kg}$ of 135 raw mixture. The starter cultures, $0.25 \mathrm{~g} / \mathrm{kg}$ of $S$. carnosus and $0.25 \mathrm{~g} / \mathrm{kg}$ of the 136 bioprotective culture, were added to the raw mixtures dispersed in $28 \mathrm{~mL}$ of cold spring 137 water, in accordance with the experimental design (Table 1). The same amount of 138 spring water was added to the raw mixtures without starter cultures. After this addition, 
each batch was manually mixed for 5 minutes. The six batches were then divided in 140 two, resulting in 12 batches of $3.88 \mathrm{~kg}$, and samples of each batch were taken 141 aseptically for microbiological analysis. The meat was then stored at $4 \pm 2{ }^{\circ} \mathrm{C}$ until the 142 following day.

143 After storage, the nitrite source $\left(50 \mathrm{~mL}\right.$ of a dilution of pure $\mathrm{NaNO}_{2}(5.66 \mathrm{mg}$ $\left.144 \mathrm{NaNO}_{2} / \mathrm{mL}\right)$ or $\mathrm{VC}(0.26 \mathrm{~g}$ vegetable concentrate $/ \mathrm{mL})$ was added to the batches in 145 accordance with the experimental design (Table 1$)$. Ascorbic acid $(0.5 \mathrm{~g} / \mathrm{kg})$ was added 146 together with the nitrite sources. Subsequently, the raw mixtures were manually mixed 147 for 2 minutes and stuffed into natural casings (50-55 $\mathrm{mm}$ in diameter). To check nitrite 148 dose, samples from these 12 mixtures were finely ground (Retsch knife mill), vacuum 149 packed in high-barrier multilayer bags (Cryovac ${ }^{\circledR}$ BB325; approximately $20 \mathrm{~g}$ 150 meat $/ \mathrm{bag}$ ) and stored at $-25{ }^{\circ} \mathrm{C}$ until nitrate and nitrite analysis. The $\mathrm{pH}$ of the $12 \mathrm{raw}$ 151 mixtures was also determined. Five sausages per treatment weighing around $500 \mathrm{~g}$ were 152 fermented for $12 \mathrm{~h}$ at $16{ }^{\circ} \mathrm{C}$ or $4{ }^{\circ} \mathrm{C}$ in accordance with the experimental design (Table 153 1). After this period, samples were taken aseptically for microbiological analysis and the $154 \mathrm{pH}$ was measured again. Sausages were then vacuum packed (Cryovac ${ }^{\circledR}$ HT3050; 325 155 x $550 \mathrm{~mm}$; permeability to oxygen, $15 \mathrm{~cm}^{3} \cdot \mathrm{m}^{-2} \cdot \mathrm{day}^{-1} \cdot \mathrm{bar}^{-1}$ at $23{ }^{\circ} \mathrm{C}$ and $0 \% \mathrm{RH}$ ) and 156 cooked in a cooking pot containing $50 \mathrm{~L}$ of tap water as follows: first, they were heated 157 at $40{ }^{\circ} \mathrm{C}$ for $2 \mathrm{~h}$, after which the temperature was increased to $60{ }^{\circ} \mathrm{C}$ and maintained at 158 this temperature for $2 \mathrm{~h}$; the temperature was then increased to $78^{\circ} \mathrm{C}$ until the interior of 
159 the sausage reached a temperature of $72{ }^{\circ} \mathrm{C}$. The sausages were then removed from the 160 cooking pot and allowed to cool at room temperature. Those sausages intended for 161 chemical analyses were then stored for 0,60 and 120 days at $4{ }^{\circ} \mathrm{C}$, whereas those 162 intended for sensory analysis were stored for 60 days at $4{ }^{\circ} \mathrm{C}$. Following the storage 163 period, sausages were finely ground (Robot Coupe mixer, model BX3; Jackson, MS, 164 USA), vacuum packed in high-barrier multilayer bags (Cryovac ${ }^{\circledR}$ BB325; 165 approximately $15 \mathrm{~g}$ meat/bag) and stored at $-25^{\circ} \mathrm{C}$ until analysis. Unless otherwise 166 specified, each sample was analyzed twice and the average of the obtained results was 167 treated as a single measurement.

\subsection{Moisture and $\mathrm{pH}$ determination}

169 The moisture of the samples (initial raw mixtures and cooked sausages) was determined 170 using the ISO 1442 procedure (International Organization for Standardization, 1997) 171 and used to express some of the results on a dry-weight basis. The measurement of $\mathrm{pH}$ 172 in the samples (initial raw mixtures and final raw mixtures before and after each 173 fermentation type) was carried out in quintuplicate using a $\mathrm{pH}$ meter (Crison $\mathrm{pH} 25$ 174 model; Crison Instruments, S.A., Alella, Spain); the average was treated as a single 175 measurement. 
177 The fat content of the raw mixtures was measured in accordance with the AOAC 178 Official Method 991.36 (AOAC, 2000). The fatty acid composition of raw mixtures was 179 determined by gas chromatography (Bou et al., 2005). First, lipid extraction was carried 180 out with $20 \mathrm{~mL}$ chloroform/methanol $(2: 1, \mathrm{v} / \mathrm{v})$ in $1.5 \mathrm{~g}$ raw mixture, which was 181 subsequently re-extracted twice using $10 \mathrm{~mL}$ of the same solvent mixture each time. 182 Fatty acid methyl esters were then prepared from this fraction using sodium methoxide 183 and $\mathrm{BF}_{3}$. Fat content was expressed on a fresh-weight basis, whereas fatty acid 184 composition was expressed as a percentage of area normalization.

\subsection{Microbiological analysis}

186 Twenty-five grams of either raw mixture or fermented sausage were taken aseptically 187 and homogenized with $75 \mathrm{~mL}$ of buffered peptone water (BPW; OXOID, Basingstoke, $188 \mathrm{UK}$ ) for $2 \mathrm{~min}$ in an IUL masticator (IUL S.A., Barcelona, Spain). Serial decimal 189 dilutions were made in sterile Ringer $1 / 4$ solution (Scharlau, Barcelona, Spain). The 190 following food-borne pathogens were determined in the raw sausages: Escherichia coli 191 was enumerated on MacConkey agar (OXOID) and Staphylococcus aureus on Mannitol 192 salt agar (MSA; OXOID); and the population of sulfite-reducing clostridia was 193 determined by counting on SPS agar (Scharlau) anaerobically. All agars were incubated 194 at $37^{\circ} \mathrm{C}$ for $48 \mathrm{~h}$. Oxidase test, growth on EMB agar (OXOID), the indole test (Bell et al. 2005) and API 20E identification strips (bioMérieux) were used to identify lactosepositive colonies on MacConkey agar. DNAse and catalase production, the coagulase 
test (Bell et al. 2005) and API STAPH identification strips (bioMérieux) were used to 198 identify mannitol-positive colonies on MSA. The absence of Salmonella was 199 determined by pre-enrichment in BPW for $16 \mathrm{~h}$ at $37^{\circ} \mathrm{C}$, enrichment in Selenite Cystine 200 Broth (OXOID) for $24 \mathrm{~h}$ at $37^{\circ} \mathrm{C}$ and in Rappaport Vassiliadis Broth (OXOID) for $24 \mathrm{~h}$ 201 at $42{ }^{\circ} \mathrm{C}$, and isolation on SS agar (OXOID) and DCLS agar (OXOID). Both agars were 202 incubated for $48 \mathrm{~h}$ at $37^{\circ} \mathrm{C}$. Kligler Iron agar (OXOID), Lysine Iron agar (OXOID), 203 Urease Broth (OXOID) and API 20E system (bioMérieux España) were used to identify 204 colonies grown on SS agar and/or DCLS agar. Starter bacteria were analyzed before and 205 after fermentation by spread plating on MRS agar (OXOID) for lactic acid bacteria and 206 on MSA (OXOID) for staphylococci. Both cultures were incubated at $30^{\circ} \mathrm{C}$ for 3 days. 207 Colonies from countable plates were initially tested for morphology, Gram stain, 208 catalase production and nitrate reductase activity (Bell et al., 2005). The API STAPH 209 system (bioMérieux) was used to identify Micrococcaceae. Gram stain and API 20C 210 AUX identification strips (bioMérieux) were used to identify yeasts grown on MRS 211 agar plates. Microorganisms are destroyed by cooking, and therefore lactobacilli and 212 total staphylococci were not analyzed at the different storage time points.

\subsection{Nitrate and nitrite determination}

214 Determination of the residual nitrate and nitrite contents was based on Griess reaction 215 method as described elsewhere (Magrinya et al., 2009). Nitrate and nitrite determination 
216 was carried out in the raw mixtures after the addition of nitrite sources and in the

217 sausages following different lengths of storage.

$218 \quad$ 2.8. Total and cured pigment analysis

219 The mononitrosylhemochrome and total pigment concentrations of the cooked sausages 220 were measured after extraction in $80 \%$ acetone and acidified acetone, respectively, 221 using the Hornsey's method (Wrolstad, 2005).

\section{2.9. Color measurements}

223 Color was measured using a Konica Minolta Chroma-Meter (model CR-410; Konica 224 Minolta Sensing Inc., Osaka, Japan) based on the CIE $L^{*} a^{*} b^{*}$ color space. CIE 225 (Commission Internationale de l'Eclairage) $L^{*}$ (lightness), $a^{*}$ (redness/greenness) and $226 b^{*}$ (yellowness/blueness) were determined from five different random surfaces of the 227 ground cooked sausages and the average of each parameter was treated as a single 228 measurement. The instrument was set for illuminant D-65 and at a $2^{\circ}$ observer angle and 229 standardized using a standard white plate. The CIE $L^{*} a^{*} b^{*}$ color space was transformed 230 into the $L^{*} C^{*} h$ color space, where $L^{*}$ represents lightness, $C^{*}$ represents chroma, and $h$ 231 represents the hue angle, as described elsewhere (Magrinya et al., 2012).

232 2.10. Tocopherol and tocotrienol determination 
233 Tocopherols and tocotrienols were determined by HPLC as described elsewhere 234 (Magrinya et al., 2012). Two grams of ground raw mixture or sausage samples were 235 saponified at $70{ }^{\circ} \mathrm{C}$ for 30 minutes with methanolic $\mathrm{KOH}$. Then, the unsaponifiable 236 matter was extracted with petroleum ether. The extract was filtered, evaporated and 237 dissolved in n-hexane prior to HPLC determination. Results were expressed as $\mathrm{mg}$ of 238 each tocopherol or tocotrienol per $\mathrm{kg}$ on a dry-weight basis.

\section{2.11. Oxidative status and susceptibility to oxidation}

240 The ferrous oxidation-xylenol orange (FOX) method was used to measure the lipid 241 hydroperoxide (LHP) content and the susceptibility of the samples to oxidation after 242144 hours of incubation to assess the samples' susceptibility to oxidation, as described 243 elsewhere (Tres et al., 2009). This latter induced FOX assay to measure susceptibility to 244 oxidation was carried out only once in the non-stored cooked sausages. Thiobarbituric 245 acid (TBA) values were determined to assess secondary oxidation after the acid aqueous 246 extraction of the samples through third-derivative spectrophotometry (Grau et al., 247 2000). LHP content and TBA values were determined in all cooked sausages.

248 2.12. Sensory analysis

249 Samples stored at $4{ }^{\circ} \mathrm{C}$ for 60 days were randomly presented to the participants in a 250 balanced incomplete block design (Cochran and Cox, 1957): 12 blocks, five samples 251 per block and five replicates for each sample treatment. This design was performed in 
252 triplicate by using 36 members from the institute to evaluate the overall acceptability of

253 the product. The selection criteria were to consume this type of product or other cooked

254 cured meat products and be familiarized with acceptance tests. Each panelist evaluated

255 the acceptability of a blind control (in total six samples were given to each panelist),

256 which was a commercial sausage. Each panelist had several slices of the samples and

257 the blind control sausage, which were placed on white plastic dishes, identified by

258 random three-digit numbers. Water and unsalted crackers were provided to panelists to

259 cleanse their palates between each sample. Panelists were asked to score the overall

260 acceptability of the product on a nine-point hedonic scale. The blind control scores were

261 subtracted from their respective sample acceptability scores.

262 2.13. Statistical analyses

263 A multifactor ANOVA was used to identify differences produced by the different 264 factors in terms of sample moisture, microbial counts, $\mathrm{pH}$, residual nitrate and nitrite 265 content, mononitrosylhemochrome and total pigment concentrations, color 266 measurements, tocopherols and tocotrienols, TBA values, LHP content, susceptibility to 267 oxidation (induced FOX assay, AUC) and overall acceptability. The factors studied 268 were tocopherol extract addition ( 0 and $200 \mathrm{mg}$ of tocopherols $/ \mathrm{kg}$ ), fermentation 269 conditions for $12 \mathrm{~h} \mathrm{(at} 16^{\circ} \mathrm{C}$ with bioprotective and nitrate-reducing cultures, at $4{ }^{\circ} \mathrm{C}$ 270 with nitrate-reducing culture and at $4{ }^{\circ} \mathrm{C}$ without starter cultures), nitrite source (pure 271 sodium nitrite or VC) and storage time (0,60 and 120 days at $\left.4{ }^{\circ} \mathrm{C}\right)$. Microbiological 
272 analyses, $\mathrm{pH}$ measurement and induced FOX assay were only conducted before storage, 273 and overall acceptability was evaluated only after 60 days of storage. Interactions 274 between more than two factors were ignored. When significant interactions were found 275 between two factors, a series of one-way ANOVAs (for factors with more than two 276 levels) or $t$-tests (for factors with two levels) were performed for each factor by fixing 277 the other factor at each specific level. In all cases, $\mathrm{P} \leq 0.05$ was considered significant. 278 When significant differences were found through the multifactor or one-way ANOVAs, 279 the least-squares means and means were separated using Scheffé's test $(\alpha=0.05)$.

\section{RESULTS AND DISCUSSION}

3.1. Moisture, crude fat, fatty acid composition, $\mathrm{pH}$ and tocopherol and tocotrienol content of raw mixtures

283 The moisture of both raw mixtures, with and without tocopherol extract, was $28465.5 \pm 0.4 \%$. The crude fat content of the raw mixture was $12.9 \pm 0.24 \%$ with tocopherol 285 extract and $13.4 \pm 0.28 \%$ without tocopherol extract. The relative percentages of 286 saturated fatty acids, monounsaturated fatty acids and polyunsaturated fatty acids of the 287 raw mixture with the addition of the tocopherol extract were $38.29,49.56$, and $12.15 \%$, 288 respectively, whereas for the raw mixture without the addition of the tocopherol extract, 289 they were $38.70,49.26$, and $12.04 \%$, respectively. The pHs of raw mixtures with and 290 without tocopherol extract were $5.72 \pm 0.06$ and $5.72 \pm 0.07$, respectively. Therefore, the 
291 moisture, crude fat content, fatty acid composition and $\mathrm{pH}$ did not differ significantly 292 between raw mixtures.

293 The $\alpha$-tocopherol, $\beta$-tocopherol, $\gamma$-tocopherol, and $\alpha$-tocotrienol content in the raw 294 mixture without tocopherol extract averaged $10.7 \pm 0.73,0.33 \pm 0.038,0.31 \pm 0.031$ and $2950.40 \pm 0.010 \mathrm{mg} / \mathrm{kg}$, expressed as dry weight, respectively, whereas in the raw mixture 296 containing the tocopherol extract the $\alpha$-tocopherol, $\beta$-tocopherol, $\gamma$-tocopherol, and $\delta$ 297 tocopherol averaged $81.5 \pm 6.31,8.1 \pm 2.58,209 \pm 10.6$ and $31.1 \pm 2.08 \mathrm{mg} / \mathrm{kg}$.

\subsection{Microbiological analyses and $\mathrm{pH}$ determination}

299 The raw mixtures were checked for the presence of food-poisoning bacteria. E. coli and 300 S. aureus accounted for less than $4 \times 10^{2} \mathrm{cfu} / \mathrm{g}$; Salmonella sp. was absent in $25 \mathrm{~g}$; and 301 sulfite-reducing clostridia accounted for less than $10 \mathrm{cfu} / \mathrm{g}$. Raw mixtures met 302 microbiological standards for raw minced meat.

303 Lactobacilli and total staphylococci were analyzed in raw mixtures following the 304 addition of the starters and in sausages after the three types of fermentation. In type A, a 305 mixture of L. sakei, S. xylosus and S. carnosus was added to the raw mixtures at $10^{6}$ $306 \mathrm{cfu} / \mathrm{g}$, as recommended by the manufacturer, and sausages were fermented at $16{ }^{\circ} \mathrm{C}$ for 30712 h. In type B, only S. carnosus starter culture was added and fermentation was 308 conducted at $4{ }^{\circ} \mathrm{C}$ for $12 \mathrm{~h}$. This time and temperature conditions are currently used not 309 only in the production of this sausage but also in the production of cooked ham. In type 
$310 \mathrm{C}$, the sausages were kept at $4{ }^{\circ} \mathrm{C}$ for $12 \mathrm{~h}$ without the addition of starter cultures and 311 thus serves as a negative control of the latter. Table 2 summarizes the results obtained 312 from the fermented sausages. The lactobacilli and staphylococci were affected by the 313 fermentation type used. The highest counts of lactobacilli on MRS agar were found in 314 type A fermentation. Before fermentation the $\mathrm{pH}$ was 5.66 for all treatments. A clear 315 drop in $\mathrm{pH}$ (from 5.66 to 5.30 ) occurred after 12 hours at $16{ }^{\circ} \mathrm{C}$ using type A 316 fermentation (Table 2). L. sakei produces lactic acid and increases acidification during 317 fermentation. Therefore, the $\mathrm{pH}$ drop was due to the lactic acid produced by the starter 318 culture used.

319 There were no significant differences between the concentration of total staphylococci 320 before and after the fermentation process (data not shown). Thus the sausages fermented 321 at $4{ }^{\circ} \mathrm{C}$ (type B) had the same cfu/g as those fermented at $16^{\circ} \mathrm{C}$ (type $\mathrm{A}$ ), suggesting that 322 mild temperatures are not sufficient to promote the growth of these bacteria. However, 323 staphylococcal strains belonging to $S . x y l o s u s$ and $S$. carnosus were reported to reduce 324 nitrate to nitrite at $15^{\circ} \mathrm{C}, 20^{\circ} \mathrm{C}$ and $30^{\circ} \mathrm{C}$ (Casaburi et al., 2005; Mauriello et al., 2004; 325 Miralles et al., 1996). Thus, the residual nitrite concentration after fermentation was 326 higher in sausages fermented with $S$. carnosus at $4{ }^{\circ} \mathrm{C}$ (type B) than in those fermented 327 with two nitrate-reductase active staphylococci (S. carnosus and S. xylosus) at $16{ }^{\circ} \mathrm{C}$ 328 (type A) (Table 3). 
329 In the type $C$ sausages, the initial counts on the MRS were estimated at $5.9 \log \mathrm{cfu} / \mathrm{g}$. 330 The overgrowth of yeasts on the MRS plates and the fact that no LAB were retrieved 331 from any of the MRS plates led us to estimate LAB counts at less than $2.6 \log \mathrm{cfu} / \mathrm{g}$, 332 which was the detection limit of the agar plate method. The yeast species found in our 333 samples and identified as Candida zeylanoides, C. lipolytica and C. famata, are 334 considered psychrotrophic. C. parapsilosis was also detected in the sausage mixture. 335 The presence of these yeast species has been reported in salami, fresh sausages and 336 Spanish fermented sausages (Encinas et al., 2000; Gardini et al., 2001). The initial 337 content of staphylococci was $4.7 \log \mathrm{cfu} / \mathrm{g} ; 12$ of the isolates belonged to S. xylosus and 338 three isolates were identified as $S$. sciuri or $S$. capitis. Both, S. sciuri and S. capitis have 339 been isolated from dried fermented sausage (Papamanoli et al., 2002). Nitrate reductase 340 activity was observed for ten isolated S. xylosus strains. Our results are similar to those 341 reported by Mauriello et al. (2004) and Casaburi et al. (2005). Total counts on the MRS 342 agar plates increased by less than one $\log \mathrm{cfu} / \mathrm{g}$ after $12 \mathrm{~h}$ of fermentation. The cell 343 number increase on the MRS was due to yeasts, and the final number of lactobacilli was $3442.6 \log \mathrm{cfu} / \mathrm{g}$ (Table 2). The number of total staphylococci found after fermentation is in 345 line with that reported by Miralles et al. (1996) in naturally fermented sausages 346 produced without the addition of starter cultures. The yeasts and nitrate-reductase347 active staphylococci found in these sausages may affect product quality, although to a 348 much lesser extent than starter cultures (Mauriello et al., 2004). 
349 Sausages in which pure sodium nitrite was added contained significantly more 350 lactobacilli than sausages made with the VC (Table 2). Plants, herbs and spices have 351 been reported as sources of natural antimicrobials, and therefore the lower concentration 352 of lactobacilli could be due to the antimicrobial properties of the $\mathrm{VC}$, which is made 353 from celery and carrot (Palou et al., 2005).

\section{3.3. Nitrate and nitrite residual amounts}

355 The residual nitrate and nitrite levels in sausages are presented in Table 3. In all cases, 356 sausages fermented with S. carnosus were far below the limit established for organic 357 production in Europe (European Commission, 2008).

358 Significant differences were observed for residual nitrate and nitrite content depending 359 on fermentation type, nitrite source and storage time. Type $\mathrm{C}$ fermentation and the use 360 of $\mathrm{VC}$ as a curing agent led to higher residual nitrate levels (Table 3). There was a 361 significant interaction between the nitrite source and fermentation type for the residual 362 nitrate amount (Figure 1). As expected, sausages without starter cultures (type C) had 363 higher amounts of residual nitrate, especially in those sausages formulated with the 364 nitrate-rich VC. Although it was found that there is microbiota with nitrate reductase 365 activity in type $\mathrm{C}$ sausages, when nitrate-rich $\mathrm{VC}$ is used, a nitrate-reducing bacterial 366 culture is required for the curing process (Sebranek and Bacus, 2007; Sindelar et al., 367 2007b). 
368 Sausages produced with type B fermentation and those produced with pure sodium 369 nitrite contained higher amounts of residual nitrite (Table 3). This is because the 370 interaction between nitrite source and fermentation type significantly influenced 371 residual nitrite levels (Figure 1). Sausages formulated with VC and subjected to type C 372 fermentation contained much lower residual nitrite amounts than the corresponding 373 sausages formulated with pure $\mathrm{NaNO}_{2}$. This is because the reduction reaction from 374 nitrate to nitrite was very low when fermentation was conducted at $4{ }^{\circ} \mathrm{C}$ for $12 \mathrm{~h}$ without 375 starter cultures, and is consistent with the high amounts of residual nitrate found in 376 those sausages formulated with $\mathrm{VC}$ and fermented in these conditions (Figure 1). 377 However, when pure nitrite is added the nitrate and nitrite residual levels were alike for 378 type $\mathrm{B}$ and type $\mathrm{C}$ fermentations. On the other hand, the amounts of residual nitrite 379 found in type A and type B sausages, fermented with a nitrate-reducing starter culture 380 (S. carnosus), did not differ significantly between nitrite sources (Figure 1).

381 The depletion of nitrite during the storage of cooked cured meat products is a widely 382 recognized phenomenon (Sindelar et al., 2007a; Sindelar et al., 2007b; Krause et al., 383 2011; Terns et al., 2011a; Terns et al., 2011b), and was also observed in this study 384 (Table 3). However, residual nitrate levels showed a different pattern of behavior during 385 storage (Table 3). The regeneration of nitrate from nitrite is not uncommon in meats 386 (Magrinya et al., 2012; Sindelar et al., 2010; Terns et al., 2011a; Terns et al., 2011b; 387 Tsoukalas et al., 2011), and was attributed to an oxidative reaction between the added 
388 nitrite and various compounds present in the food matrix. The conversion to nitrate 389 upon storage is confirmed to occur in this study in which even lower ingoing amounts 390 of nitrite sources were assessed (equivalent to 70 instead of $80 \mathrm{mg} \mathrm{NaNO} / \mathrm{kg}$ ). Despite 391 this increase in residual nitrate over time, the sum of the residual nitrate and nitrite 392 levels, expressed as nitrate ion, decreased with storage time, which indicates that the 393 curing agents could be involved in curing reactions during the storage of the cooked 394 sausages.

\section{3.4. Total and cured pigment analyses}

396 The mononitrosylhemochrome concentration and curing efficiency of the sausages is 397 presented in Table 3. Cured meat products are considered acceptable when the pigment 398 conversion ratio is $80 \%$ or higher (Wrolstad, 2005). The main effects of fermentation 399 type and nitrite source were significant for nitrosylhemochrome concentration and 400 curing efficiency (Table 3). The lowest concentration of the characteristic cured 401 pigment was found in type $\mathrm{C}$ sausages to which no starter cultures were added. The 402 curing efficiency for sausages subjected to type A and B fermentations was above $80 \%$ 403 thus meaning that an optimum curing can be achieved with relatively low amounts of 404 nitrite $(70 \mathrm{mg} \mathrm{NaNO} / \mathrm{kg})$. These results are in line with previous results at nitrite 405 sources concentrations equivalent to $80 \mathrm{mg} \mathrm{NaNO} / \mathrm{kg}$ (Magrinya et al., 2012). 
406 Table 3 shows that VC affected the curing process, because those sausages in which this 407 nitrite source was used seemed to have a lower curing efficiency. However, these 408 misleading results can be explained by the interaction between the fermentation type 409 and nitrite source factors (Figure 2). Those sausages formulated with the VC in 410 combination with type $\mathrm{C}$ fermentation showed much lower concentrations of 411 nitrosylhemochrome and a much lower curing efficiency, but no differences were found 412 between the three fermentation conditions when pure sodium nitrite was used (Figure 413 2). Therefore, with type $\mathrm{C}$ fermentation only it is possible to produce organic botifarra 414 catalana with an appropriate curing efficiency with the addition of pure nitrite at 70 $415 \mathrm{mg} / \mathrm{kg}$. As expected, when the sausages were formulated with a nitrate-rich $\mathrm{VC}$ as a 416 source of nitrite, the lack of a starter culture with nitrate reductase activity resulted in 417 sausages with much lower levels of cured pigment, which demonstrates the crucial role 418 of $S$. carnosus during fermentation in producing cooked cured sausages when this 419 source of nitrite is used (Casaburi et al., 2005). These results suggest that when pure 420 nitrite is added it may be possible to produce sausages with an optimal curing by 421 cooking them immediately. That means the omission of the storage at $4{ }^{\circ} \mathrm{C}$ and, in 422 consequence, the elaboration of botifarra catalana under faster processing conditions 423 than those of type A. In case that a nitrate source is added, then it is necessary to use $S$. 424 carnosus but the effects of the omission of storage at $4{ }^{\circ} \mathrm{C}$ and, therefore, the direct 425 submission of sausages to a progressive cooking should be assessed. However, it should 
426 be borne in mind that these faster production processes may affect to the aroma and

427 flavor development of this product typically fermented at low temperatures and, in 428 consequence, the acceptability of these products should be considered.

\subsection{Color measurements}

430 The fermentation type and nitrite source factors influenced all of the studied 431 instrumental color parameters (Table 3). Lightness $\left(L^{*}\right)$ was higher in type A sausages 432 fermented at $16{ }^{\circ} \mathrm{C}$ for $12 \mathrm{~h}$ with the bioprotective starter culture (L. sakei and $S$. 433 xylosus) and the nitrate-reducing culture (S. carnosus). The color and texture of the 434 sausages depended on protein denaturation caused by the decline in $\mathrm{pH}$ and heat 435 treatments. With respect to the decline in $\mathrm{pH}$, it has been reported that salami fermented 436 with lactic acid bacteria resulted in higher $L^{*}$ and $a^{*}$ values (Barbut, 2010). The author 437 also found that cooked sausages had higher $L^{*}$ values than raw meat mixtures. 438 Therefore, it is reasonable that those sausages initially fermented at $16{ }^{\circ} \mathrm{C}$ for $12 \mathrm{~h}$ 439 having lower $\mathrm{pH}$ values (Table 2) resulted in higher $L^{*}$ after cooking when compared 440 with other sausages in which there was no obvious decline in $\mathrm{pH}$. Increased redness was 441 found in those sausages fermented with $S$. carnosus, regardless of fermentation 442 temperature. The $a *$ value is related to visible redness in meat and the content of 443 nitrosylhemochrome (Barbut, 2010). Therefore, the lower $a^{*}$ value in sausages without 
444 starter cultures (type C) could be explained by the lack of nitrate-to-nitrite conversion 445 and the inhibition of the subsequent curing process.

446 According to the results shown in Table 3, the addition of pure sodium nitrite to the 447 sausage formula as a curing agent produced darker and redder sausages with higher 448 color saturation. This is consistent with Krause et al. (2011), who found that hams 449 formulated with pure sodium nitrite had a more intense cured color than those cured 450 with vegetable juice powder. In addition, a significant interaction between the 451 fermentation type and nitrite source was found for the color parameters (Figure 3). 452 Therefore, as mentioned above, when sausages were formulated with VC, nitrate was 453 efficiently reduced to nitrite by the nitrate-reducing starter culture and consequently the 454 cured pigment was efficiently formed in these sausages (Figures 1 and 2). As a result, 455 these sausages had the same $a^{*}$ values as those sausages produced using pure sodium 456 nitrite (Figure 3). Terns et al. (2011b) reported similar results in cooked cured sausages. 457 The interactions found for the hue angle and chroma values are probably also a 458 consequence of the intense nitrate reductase activity of the $S$. carnosus culture. In 459 addition, several authors (Terns et al., 2011a; Terns et al., 2011b; Tsoukalas et al., 2011; 460 Magrinya et al., 2012) have found that similar VC produced lighter and yellower 461 sausages compared to those made with pure sodium nitrite, and this was also attributed 462 to the intrinsic color of the powder. 
463 The color of the sausages was constant throughout storage. Likewise, lightness and 464 yellowness have been reported to show no consistent variations in vacuum-packed 465 bologna sausages (Carballo et al., 1991) and sliced ham (Krause et al., 2011) stored for 46642 or more days in the dark under refrigeration. However, the decrease in $a^{*}$ values 467 during storage has been reported in vaccum-packed cured sausages (Terns et al., 2011b) 468 and also in botifarra catalana (Magrinya et al., 2012) that was associated with 469 degradation of the cured pigment. In other studies $a^{*}$ values increased during storage 470 and this was explained by the fact that residual nitrite reacted with myoglobin during 471 storage and produced colored pigments (Terns et al., 2011a; Sindelar et al., 2007b). The 472 fact that the amount of cured sausage pigment in the present study was constant during 473 storage (Table 3) could explain the color stability of botifarra catalana during vacuum474 packed refrigerated storage. The decrease in the sum of residual nitrate and nitrite 475 amounts observed during storage of the cooked sausages in this study seems to be in 476 agreement with their role as a reservoir to maintain red color.

\section{3.6. Tocopherol and tocotrienol content}

478 The tocopherol content of the sausages is reported in Table 4. The addition of the 479 tocopherol extract to the formula led to significant changes in amounts of the different 480 tocopherols in the sausages. The extract is particularly rich in $\gamma$-tocopherol (Table 1 481 footnote), which explains the high content of this tocopherol in sausages and the raw 482 mixture containing this tocopherol extract. It is interesting to note that the cooking 
483 procedure had no significant effect on the tocopherol content. Therefore, it is possible to 484 add a tocopherol extract to raw meat mixtures to produce cooked cured sausages 485 enriched with tocopherols. The interactions between the other studied factors had no 486 significant effects on the tocopherol and tocotrienol content of the sausages.

\subsection{Oxidative status and susceptibility to oxidation}

488 The LHP content of the sausages is shown in Table 4. In comparison with other studies 489 (Magrinya et al., 2012; Magrinya et al., 2009), the LHP content was low, but significant 490 enough to show differences based on fermentation type and storage time. Type C 491 sausages contained the highest amounts of LHP. It is well known that nitrite acts as an 492 antioxidant in cured meats (Pegg and Shahidi, 2000). Therefore, the absence of nitrate493 reducing starter cultures in samples containing nitrate, provided by means of the $\mathrm{VC}$, 494 decreased the formation of nitrite thus explaining the higher LHP content.

495 With respect to secondary oxidation, no significant differences were found in the TBA 496 values of sausages for the main factors studied (Table 4). TBA values were higher than 497 those found in a previous study (Magrinya et al., 2012) which can be attributed to a 498 number of reasons including the lower ingoing nitrite levels. Despite that, the recorded 499 values were consistent with other studies dealing with other cooked cured meat products 500 (Parra et al., 2010). 
501 In dry-fermented sausages, the addition of tocopherol extract was found to prevent 502 oxidation (Magrinya et al., 2009). However, in the present study, it had no significant 503 effect during the production and storage of botifarra catalana. This difference is 504 probably due to the short time elapsed between the addition of the tocopherol extract 505 and the vacuum packaging of the catalana sausages in low permeability plastic bags. 506 Various authors have reported that hams manufactured from pigs whose diet was 507 supplemented with $\alpha$-tocopheryl acetate exhibited a higher degree of oxidative stability 508 during retail storage (DeWinne and Dirinck, 1997; Dineen et al., 2000). This could be 509 also related to the fact that dietary supplementation with tocopheryl acetate has already 510 been shown to be more effective against oxidation than the post mortem addition of 511 tocopherol to meat (Jensen et al., 1998).

512 TBA values did not increase significantly during storage, as other authors have also 513 found for vacuum-packed cured meat products (Carballo et al., 1991; Dineen et al., 514 2000; Parra et al., 2010). One explanation could be the higher oxidative stability of 515 vacuum-packed cured products. Furthermore, sodium nitrite has been shown to be an 516 effective antioxidant at levels as low as $50 \mathrm{mg} / \mathrm{kg}$ of ingoing nitrite (Pegg and Shahidi, 517 2000).

518 3.8. Sensory analysis 
519 The results for the overall acceptability test carried out after 60 days storage at $4 \pm 2{ }^{\circ} \mathrm{C}$ 520 in vacuum-packed sealed bags are shown in Table 4 . There were no differences in the 521 overall acceptability of the sausages containing the tocopherol extract compared with 522 control sausages (Table 4). In hams, De Winne and Dirinck (1997) found differences 523 between the control and those with a higher content of $\alpha$-tocopherol using a triangle test 524 and a paired comparison. The results indicated that the supplemented ham had a fresher 525 odor and taste and these attributes were related to lipid oxidation. TBARS values of 0.5 526 to $1.0 \mathrm{mg} / \mathrm{kg}$ have been suggested as the threshold for oxidized odor and 1.0 to 2.0 $527 \mathrm{mg} / \mathrm{kg}$ for oxidized flavor (Tarladgis et al., 1960). Therefore, the fact that all TBA 528 values were within the oxidized odor level and did not differ between treatments (Table 529 4) could explain why panelists found no differences between sausages with and without 530 the tocopherol extract.

531 Meat-purchasing decisions are influenced by color more than any other quality factor 532 since consumers use discoloration as an indicator of freshness and wholesomeness. This 533 may explain why those sausages with the lowest scores presented less redness and 534 chroma and a higher hue angle (Table 3). In this respect, the lack of nitrate-reducing 535 culture is crucial for color development upon the addition of $\mathrm{VC}$ and thus negatively 536 affects overall acceptability.

537 Therefore, the use of nitrate reductase cultures not only helps develop a cured color but 538 may also influence on overall acceptability. In fact, in a previous study, panelists 
preferred botifarra catalana made with the same $\mathrm{VC}$ at $0.33 \%$, even though sausages

540 made with pure sodium nitrite were slightly redder (Magrinya et al., 2012). In hams,

541 trained panelists indicated that a vegetable aroma from $\mathrm{VC}$ can be detected when this 542 was added at concentrations about $0.3 \%$ (Sindelar et al., 2007a). Moreover, in 543 comparison with the addition of pure sodium nitrite, consumers showed no preference 544 in terms of overall acceptability for emulsified cooked sausages with added vegetable 545 juice powder at $0.2 \%$ (Terns et al., 2011b). Thus, it is not clear whether consumers 546 could detect the presence of VC and whether they had a preference for these sausages, 547 but no dislike was expressed as long as the color was sufficiently red.

548

549 To conclude, it is possible to manufacture organic cooked cured sausages without the 550 addition of pure nitrite. In case of omission of pure nitrite, nitrate-rich VC can be used 551 as curing agents in fermented meat products. However, residual nitrate and nitrite 552 should be minimized to avoid nitrosamine formation. The use of nitrate-reducing 553 bacteria is an interesting approach to reducing these residual amounts and controlling 554 curing reactions, even when the only curing agent used is nitrite. In the presence of 555 nitrate, the addition of nitrate-reducing cultures caused the appropriate curing of the 556 meat product and helped to decrease the formation of hydroperoxides. Conversely, the 557 addition of tocopherols in our conditions was found to have no effect on oxidative status 
1

2

3

4

5

6

7

8

9

10

11

12

13

14

15

16

17

18

19

20

21

22

23

24

25

26

27

28

29

30

31

32

33

34

35

36

37

38

39

40

41

42

43

44

45

46

47

48

49

50

51

52

53

54

55

56

57

58

59

60

558 and acceptability scores. Therefore, it is advisable to produce organic botifarra catalana

559 using $\mathrm{VC}$ in combination with cultures with intense nitrate reductase activity.

560 
1

2

3

4

5

6

7

8

9

10

11

12

13

14

15

16

17

18

19

20

21

22

23

24

25

26

27

28

29

30

31

32

33

34

35

36

37

38

39

40

41

42

43

44

45

46

47

48

49

50

51

52

53

54

55

56

57

58

59

60

\section{FIGURE CAPTIONS:}

562

563 Fig. 1 Interaction between fermentation type and nitrite source for the residual nitrate

564 and nitrite content in cooked sausages

565

566 Fig. 2 Interaction between fermentation type and nitrite source for nitrosylhemochrome

567 concentration and curing efficiency in cooked sausages

568

569 Fig. 3 Interaction between fermentation type and nitrite source for lightness (L*),

570 redness $\left(\mathrm{a}^{*}\right)$, chroma $\left(\mathrm{C}^{*}\right)$ and hue angle $(\mathrm{h})$ in cooked sausages 
572

573

574

575

576

577

578

579

580

581

582

583

584

585

586

587

588

589

590

591

592

593

594

595

596

597

598

599

600

601

602

603

604

\section{REFERENCES:}

AOAC. (2000) Official methods of analysis of AOAC International (17th ed.). Official Method 991.36. Gaithersburg (Md.): AOAC International: AOAC International.

Barbut S. (2010) Color Development during natural fermentation anc chemical acidification of salami-type products. Journal of Muscle Foods 21(3): 499-508.

Bell C, Neaves P and Williams AP. (2005) Food microbiology and laboratory practice, Oxford: Wiley-Blackwell.

Bou R, Codony R, Tres A, et al. (2005) Increase of geometrical and positional fatty acid isomers in dark meat from broilers fed heated oils. Poultry Science 84(12): 1942-1954.

Carballo J, Cavestany M and Jiménez-Colmenero F. (1991) Effect of light on color and reaction of nitrite in sliced pork bologna under chilled storage temperatures. Meat Science 30(3): 235-244.

Casaburi A, Blaiotta G, Mauriello G, et al. (2005) Technological activities of Staphylococcus carnosus and Staphylococcus simulans strains isolated from fermented sausages. Meat Science 71(4): 643-650.

Cochran WG and Cox GM. (1957) Experimental designs, New York: John Wiley \& Sons.

DeWinne A and Dirinck P. (1997) Studies on vitamin E and meat quality .3. Effect of feeding high vitamin $\mathrm{E}$ levels to pigs on the sensory and keeping quality of cooked ham. Journal of Agricultural and Food Chemistry 45(11): 4309-4317.

Dineen NM, Kerry JP, Lynch PB, et al. (2000) Reduced nitrite levels and dietary alphatocopheryl acetate supplementation: effects on the colour and oxidative stability of cooked hams. Meat Science 55(4): 475-482.

Encinas JP, Lopez-Diaz TM, Garcia-Lopez ML, et al. (2000) Yeast populations on Spanish fermented sausages. Meat Science 54(3): 203-208.

European Commission. (2006) Directive 2006/52/EC of the european parliament and of the council of 5 july 2006 amending directive 95/2/EC on food additives other than colours and sweeteners and directive $94 / 35 / \mathrm{EC}$ on sweeteners for use in foodstuffs. L 204/10. Official Journal of the European Union.

European Commission. (2008) Commission regulation (EC) no 889/2008 of 5 september 2008 laying down detailed rules for the implementation of council regulation (EC) no 834/2007 on organic production and labelling of organic 
products with regard to organic production, labelling and control. L 250/1. Official Journal of the European Union.

Gardini F, Suzzi G, Lombardi A, et al. (2001) A survey of yeasts in traditional sausages of southern Italy. Fems Yeast Research 1(2): 161-167.

Grau A, Guardiola F, Boatella J, et al. (2000) Measurement of 2-thiobarbituric acid values in dark chicken meat through derivative spectrophotometry: Influence of various parameters. Journal of Agricultural and Food Chemistry 48(4): 11551159.

Hammes WP. (2012) Metabolism of nitrate in fermented meats: The characteristic feature of a specific group of fermented foods. Food Microbiology 29(2): 151156.

International Organization for Standardization. (1997) Meat and meat products: Determination of moisture content (reference method). ISO 1442:1997. Geneva, Switzerland.

Jensen C, Lauridsen C and Bertelsen G. (1998) Dietary vitamin E: Quality and storage a stability of pork and poultry. Trends in Food Science \& Technology 9(2): 62-72.

Krause BL, Sebranek JG, Rust RE, et al. (2011) Incubation of curing brines for the production of ready-to-eat, uncured, no-nitrite-or-nitrate-added, ground, cooked and sliced ham. Meat Science 89(4): 507-513.

Magrinya N, Bou R, Rius N, et al. (2012) Effect of Fermentation Time and Vegetable Concentrate Addition on Quality Parameters of Organic Botifarra Catalana, a Cured-Cooked Sausage. Journal of Agricultural and Food Chemistry 60(27): 6882-6890.

Magrinya N, Bou R, Tres A, et al. (2009) Effect of Tocopherol Extract, Staphylococcus carnosus Culture, and Celery Concentrate Addition on Quality Parameters of Organic and Conventional Dry-Cured Sausages. Journal of Agricultural and Food Chemistry 57(19): 8963-8972.

Mauriello G, Casaburi A, Blaiotta G, et al. (2004) Isolation and technological properties of coagulase negative staphylococci from fermented sausages of Southern Italy. Meat Science 67(1): 149-158.

Miralles MC, Flores J and PerezMartinez G. (1996) Biochemical tests for the selection of Staphylococcus strains as potential meat starter cultures. Food Microbiology 13(3): 227-236.

Palou E, Alzamora SM and Lopez-Malo Vigil A. (2005) Naturally occurring compounds - plant sources. In: Davidson PM, Sofos JN and Branen AL (eds) Antimicrobials in foods. Boca Raton, Florida: CRC Press, 429-451. 
Papamanoli E, Kotzekidou P, Tzanetakis N, et al. (2002) Characterization of Micrococcaceae isolated from dry fermented sausage. Food Microbiology 19(5): 441-449.

Parra V, Viguera J, Sanchez J, et al. (2010) Modified atmosphere packaging and vacuum packaging for long period chilled storage of dry-cured Iberian ham. Meat Science 84(4): 760-768.

Pegg RB and Shahidi F. (2000) Nitrite curing of meat: the N-nitrosamine problem and nitrite alternatives, Trumbull, CT: Food \& Nutrition Press, Inc.

Sebranek JG and Bacus JN. (2007) Cured meat products without direct addition of nitrate or nitrite: what are the issues? Meat Science 77(1): 136-147.

Sindelar JJ, Cordray JC, Sebranek JG, et al. (2007a) Effects of varying levels of vegetable juice powder and incubation time on color, residual nitrate and nitrite, pigment, $\mathrm{pH}$, and trained sensory attributes of ready-to-eat uncured ham. Journal of Food Science 72(6): S388-S395.

Sindelar JJ, Cordray JC, Sebranek JG, et al. (2007b) Effects of vegetable juice powder concentration and storage time on some chemical and sensory quality attributes of uncured, emulsified cooked sausages. Journal of Food Science 72(5): S324S332.

Sindelar JJ, Terns MJ, Meyn E, et al. (2010) Development of a method to manufacture uncured, no-nitrate/nitrite-added whole muscle jerky. Meat Science 86(2): 298303.

Tarladgis BG, Watts BM, Younathan MT, et al. (1960) A distillation method for the quantitative determination fo malonaldehyde in rancid foods. Journal of the American Oil Chemists Society 37(1): 44-48.

Terns MJ, Milkowski AL, Claus JR, et al. (2011a) Investigating the effect of incubation time and starter culture addition level on quality attributes of indirectly cured, emulsified cooked sausages. Meat Science 88(3): 454-461.

Terns MJ, Milkowski AL, Rankin SA, et al. (2011b) Determining the impact of varying levels of cherry powder and starter culture on quality and sensory attributes of indirectly cured, emulsified cooked sausages. Meat Science 88(2): 311-318.

Tres A, Daniela Nuchi C, Bou R, et al. (2009) Assessing rabbit and chicken tissue susceptibility to oxidation through the ferrous oxidation-xylenol orange method. European Journal of Lipid Science and Technology 111(6): 563-573.

Tsoukalas DS, Katsanidis E, Marantidou S, et al. (2011) Effect of freeze-dried leek powder (FDLP) and nitrite level on processing and quality characteristics of fermented sausages. Meat Science 87(2): 140-145. 
677 Wood JD, Enser M, Fisher AV, et al. (2008) Fat deposition, fatty acid composition and 678 meat quality: A review. Meat Science 78(4): 343-358.

679 Wrolstad RE. (2005) Handbook of food analytical chemistry, Hoboken (New Jersey): 680 Wiley-Interscience.

681

682 


\title{
Table 1. Sausage treatments
}

\author{
${\text { Tocopherols }(\mathrm{mg} / \mathrm{kg})^{\mathrm{a}}}^{\text {Fermentation }^{\mathrm{b}}}$ Nitrite source $^{\mathrm{c}}$ \\ 200 \\ Type A \\ Pure sodium nitrite \\ 200 \\ Type A \\ Vegetable concentrate \\ 200 \\ Type B \\ Pure sodium nitrite \\ 200 \\ Type B \\ Vegetable concentrate \\ 200 \\ Type C \\ Pure sodium nitrite \\ 200 \\ Type C \\ Vegetable concentrate \\ 0 \\ Type A \\ Pure sodium nitrite \\ 0 \\ Type A Vegetable concentrate \\ 0 \\ Type B \\ Pure sodium nitrite \\ 0 \\ Type B Vegetable concentrate \\ 0 \\ Type C \\ Pure sodium nitrite \\ 0 \\ Type C \\ Vegetable concentrate \\ ${ }^{\text {a }}$ Expressed as average sum of tocopherols in $\mathrm{mg} / \mathrm{kg}$ of raw mixture. The tocopherol extract contained $\alpha$-, \\ $\beta-, \gamma$-, and $\delta$-tocopherols at the concentrations of $82 \pm 2,8.2 \pm 0.3,293 \pm 9$, and $110 \pm 2 \mathrm{~g} / \mathrm{kg}$, respectively. \\ ${ }^{\mathrm{b}}$ Three different fermentation types, where A involved $12 \mathrm{~h}$ at $16^{\circ} \mathrm{C}$ and contained a bioprotective starter \\ culture, Lactobacillus sakei and Staphylococcus xylosus, and a nitrate-reducing culture, Staphylococcus \\ carnosus; B involved $12 \mathrm{~h}$ at $4{ }^{\circ} \mathrm{C}$ and contained a nitrate-reducing culture, Staphylococcus carnosus; and \\ $\mathrm{C}$ involved $12 \mathrm{~h}$ at $4{ }^{\circ} \mathrm{C}$ and no starter cultures. \\ ${ }^{\mathrm{c}}$ Addition of pure $\mathrm{NaNO}_{2}$ or vegetable concentrate, each providing the equivalent of $70 \mathrm{mg} \mathrm{NaNO} / \mathrm{kg}$ \\ raw mixture.
}


Table 2. Effect of addition of tocopherol extract, fermentation type and nitrite source on microbial counts and pH of fermented botifarra catalana before cooking. ${ }^{\text {a }}$

\begin{tabular}{|c|c|c|c|}
\hline & $\begin{array}{l}\text { Lactobacilli } \\
(\log c f u / g)^{b}\end{array}$ & $\begin{array}{l}\text { Staphylococci } \\
(\log \mathrm{cfu} / \mathrm{g})^{\mathrm{c}}\end{array}$ & $\begin{array}{c}\text { pH after } \\
\text { fermentation }\end{array}$ \\
\hline \multicolumn{4}{|c|}{ Tocopherol (mg/kg) } \\
\hline 0 & 5.38 & 5.94 & 5.52 \\
\hline 200 & 5.45 & 5.76 & 5.55 \\
\hline SEM & 0.021 & 0.108 & 0.010 \\
\hline
\end{tabular}

Fermentation

Type A

$7.68 \mathrm{z}$

$6.30 \mathrm{y}$

$5.30 \mathrm{x}$

Type B

$5.95 \mathrm{y}$

$6.35 \mathrm{y}$

$5.62 \mathrm{y}$

Type $\mathrm{C}$

$2.60 x$

$4.90 \mathrm{x}$

$5.68 \mathrm{y}$

SEM

0.026

0.132

0.013

Nitrite source

$\begin{array}{llll}\text { Pure sodium nitrite } & 5.55 \mathrm{y} & 5.89 & 5.51\end{array}$

$\begin{array}{llll}\text { Vegetable concentrate } & 5.28 \mathrm{x} & 5.81 & 5.55\end{array}$

$\begin{array}{llll}\text { SEM } & 0.210 & 0.108 & 0.010\end{array}$

a The description of the different effects is provided in Table 1. Values given in this table correspond to least-squares means obtained from multifactor $\operatorname{ANOVA}(\mathrm{n}=12$ for lactobacilli, staphylococci, and $\mathrm{pH})$. Least-squares means within the same column for the same factor but with different letters differ significantly $(\mathrm{P} \leq 0.05)$.

${ }^{\mathrm{b}}$ Microbial counts expressed as the logarithm of lactobacilli colony-forming units per $\mathrm{g}$ of dried sample.

${ }^{c}$ Microbial counts expressed as the logarithm of staphylococci colony-forming units per $g$ of dried sample. 
Table 3. Effect of addition of tocopherol extract, fermentation type, nitrite source, and storage time on residual nitrate and nitrite, mononitrosylhemochrome, curing efficiency and instrumental color of cooked cured botifarra catalana ${ }^{\mathrm{a}}$.

\begin{tabular}{|c|c|c|c|c|c|c|c|c|}
\hline & \multirow{2}{*}{$\begin{array}{l}\text { Residual } \\
\text { nitrate }^{b} \\
(\mathrm{mg} / \mathrm{kg})\end{array}$} & \multirow{2}{*}{$\begin{array}{l}\text { Residual } \\
\text { nitrite }^{c} \\
(\mathrm{mg} / \mathrm{kg})\end{array}$} & \multirow{2}{*}{$\begin{array}{l}\text { Mononitrosyl- } \\
\text { hemochrome }^{\mathrm{d}} \\
(\mathrm{mg} / \mathrm{kg})\end{array}$} & \multirow{2}{*}{$\begin{array}{c}\text { Curing } \\
\text { efficiency }^{\text {e }} \\
(\%)\end{array}$} & \multicolumn{4}{|c|}{ Instrumental color $^{\mathrm{f}}$} \\
\hline & & & & & $L^{*}$ & $a^{*}$ & $\mathrm{C}^{*}$ & $\bar{h}$ \\
\hline \multicolumn{9}{|c|}{ Tocopherol } \\
\hline 0 & $10.3 \mathrm{x}$ & 2.3 & 179 & 77.8 & 63.47 & 15.73 & 17.92 & 28.70 \\
\hline 200 & $11.2 \mathrm{y}$ & 2.5 & 174 & 77.4 & 63.51 & 15.64 & 17.84 & 28.81 \\
\hline SEM & 0.32 & 0.40 & 2.0 & 0.56 & 0.094 & 0.058 & 0.042 & 0.156 \\
\hline \multicolumn{9}{|c|}{ Fermentation } \\
\hline Type A & $1.7 \mathrm{x}$ & $0.4 \mathrm{x}$ & $198 \mathrm{y}$ & $86.2 \mathrm{z}$ & $63.73 \mathrm{y}$ & $16.31 \mathrm{y}$ & $18.36 \mathrm{y}$ & $27.31 \mathrm{x}$ \\
\hline Type B & $2.5 \mathrm{x}$ & $4.5 \mathrm{y}$ & $189 \mathrm{y}$ & $83.2 \mathrm{y}$ & $63.23 x$ & $16.34 \mathrm{y}$ & $18.37 \mathrm{y}$ & $27.18 \mathrm{x}$ \\
\hline Type C & $28.0 \mathrm{y}$ & $2.3 \mathrm{x}$ & $142 \mathrm{x}$ & $63.3 \mathrm{x}$ & $63.47 \mathrm{xy}$ & $14.04 \mathrm{x}$ & $16.92 \mathrm{x}$ & $31.78 \mathrm{y}$ \\
\hline SEM & 0.39 & 0.49 & 2.5 & 0.69 & 0.115 & 0.071 & 0.051 & 0.192 \\
\hline
\end{tabular}




\begin{tabular}{lcccccccc}
\hline Nitrite source & & & & & & & & \\
Pure sodium nitrite & $5.0 \mathrm{x}$ & $3.2 \mathrm{y}$ & $191 \mathrm{y}$ & $83.6 \mathrm{y}$ & $63.24 \mathrm{x}$ & $16.47 \mathrm{y}$ & $18.44 \mathrm{y}$ & $26.71 \mathrm{x}$ \\
Vegetable concentrate & $16.6 \mathrm{y}$ & $1.7 \mathrm{x}$ & $162 \mathrm{x}$ & $71.5 \mathrm{x}$ & $63.74 \mathrm{y}$ & $14.90 \mathrm{x}$ & $17.33 \mathrm{x}$ & $30.79 \mathrm{y}$ \\
SEM & 0.32 & 0.40 & 2.0 & 0.56 & 0.094 & 0.058 & 0.042 & 0.156 \\
Storage time (days) & & & & & & & & \\
0 & $9.9 \mathrm{x}$ & $5.4 \mathrm{y}$ & 177 & 78.0 & 63.26 & 15.74 & 17.91 & 28.60 \\
60 & $11.5 \mathrm{y}$ & $1.3 \mathrm{x}$ & 173 & 76.7 & 63.54 & 15.68 & 17.89 & 28.83 \\
120 & $10.6 \mathrm{xy}$ & $0.5 \mathrm{x}$ & 180 & 78.0 & 63.68 & 15.64 & 17.85 & 28.83 \\
SEM & 0.39 & 0.49 & 2.5 & 0.69 & 0.115 & 0.071 & 0.051 & 0.192
\end{tabular}

${ }^{a}$ The description of the different effects is provided in Table 1. Values given in this table correspond to least-squares means obtained from multifactor ANOVA (each determination has a $\mathrm{n}=36$ ). Least-squares means within the same column for the same factor but with different letters differ significantly $(\mathrm{P} \leq 0.05)$.

${ }^{\mathrm{b}}$ Residual nitrate is expressed as $\mathrm{mg}$ of $\mathrm{NaNO}_{3}$ per kg of sausage.

${ }^{\mathrm{c}}$ Residual nitrite is expressed as $\mathrm{mg}$ of $\mathrm{NaNO}_{2}$ per kg of sausage.

${ }^{\mathrm{d}}$ Results are expressed as mg mononitrosylhemochrome per kg of sausage as dry weight.

${ }^{\mathrm{e}}$ Curing efficiency expressed as the percentage of the concentration of mononitrosylhemochrome divided by the concentration of total heme pigments, both concentrations expressed per kg of sausage as dry weight. 
${ }^{\mathrm{f}} \mathrm{L}^{*}$, lightness; $\mathrm{a}^{*}$, redness; $\mathrm{b}^{*}$, yellowness; chroma $\left(\mathrm{C}^{*}\right)$ is the root of the sum of the squares of $\mathrm{a}^{*}$ and $\mathrm{b}^{*}$ and is used to express color saturation; hue angle (h) is the arctangent of the quotient of $\mathrm{b}^{*} / \mathrm{a}^{*}$ and is used to express color hue $(\mathrm{h}=0$, true red; $\mathrm{h}=90$, true yellow). 
Table 4. Effect of addition of tocopherol extract, fermentation type, nitrite source, and storage time on tocopherols, lipid hydroperoxide (LHP) content, thiobarbituric acid (TBA) values, susceptibility to oxidation (AUC) and consumers' overall acceptability of cooked cured botifarra catalana ${ }^{\mathrm{a}}$.

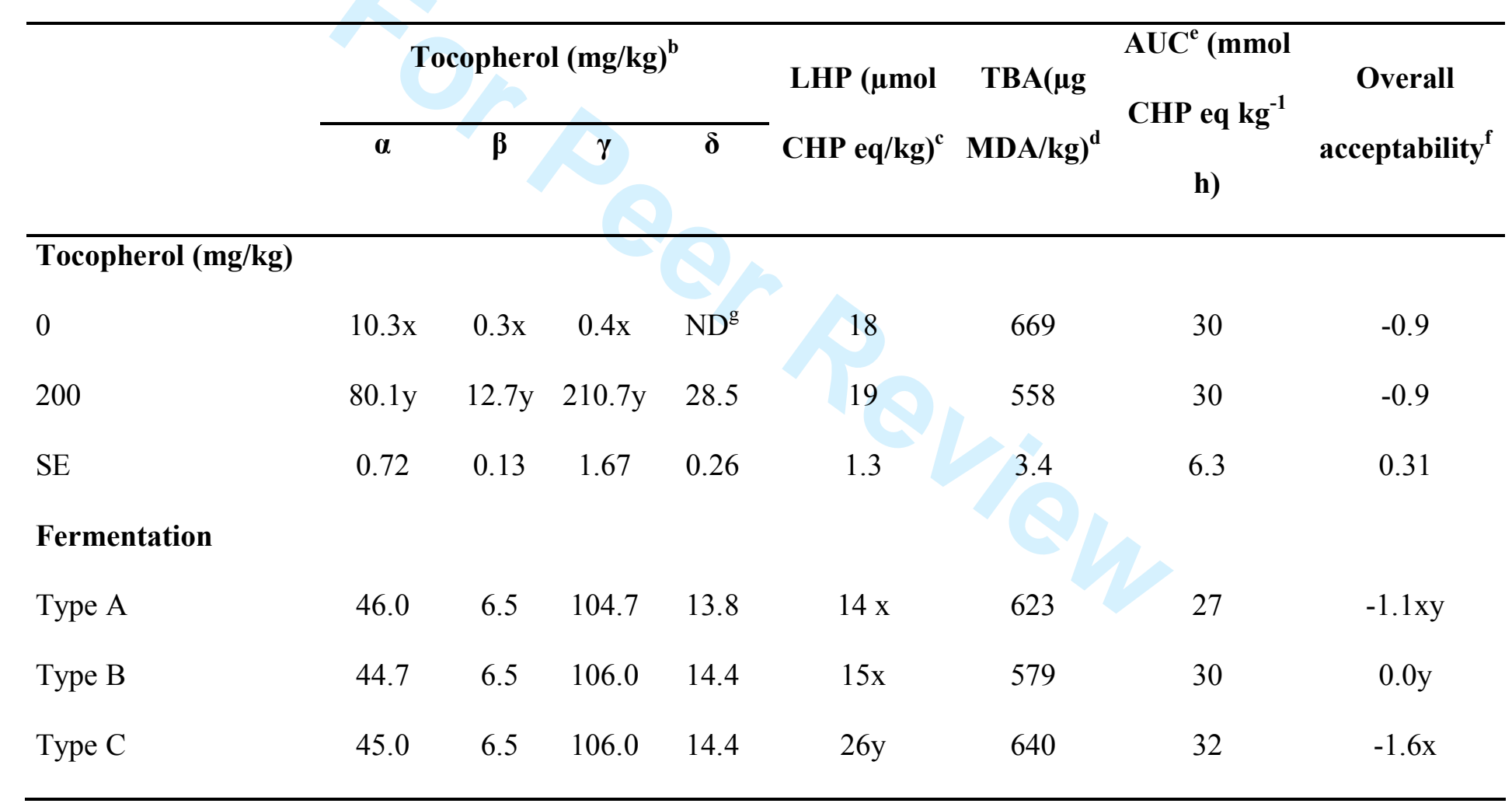




$\begin{array}{lll}0.16 & 2.05 & 0.32\end{array}$

1.6

53.1

7.7

\section{Nitrite source}

$\begin{array}{lccccccrr}\text { Pure sodium nitrite } & 45.2 & 6.3 & 105.9 & 14.1 & 16.9 & 589 & 29.6 & -0.4 y \\ \text { Vegetable concentrate } & 45.2 & 6.7 & 105.2 & 14.4 & 20.6 & 638 & 30.0 & -1.5 \mathrm{x} \\ \text { SEM } & 0.72 & 0.13 & 1.67 & 0.26 & 1.32 & 43.4 & 6.30\end{array}$

\section{Storage time (days)}

0

60

$\begin{array}{llllll}45.1 & 6.5 & 107.1 & 14.5 & 11.7 \mathrm{x} & 570 \\ 45.0 & 6.5 & 104.7 & 14.1 & 18.4 \mathrm{y} & 613 \\ 45.6 & 6.5 & 104.9 & 14.1 & 26.1 \mathrm{z} & 659 \\ 0.88 & 0.16 & 2.05 & 0.32 & 1.61 & 53.1\end{array}$

${ }^{a}$ The description of the different effects is provided in Table 1. Values given in this table correspond to least-squares means obtained from multifactor ANOVA $(\mathrm{n}=36,36$, 36, 12, and 180 for tocopherol and tocotrienol analogs, LHP, TBA values, AUC and overall acceptability, respectively). Least-squares means within the same column for the same factor but with different letters differ significantly $(\mathrm{P} \leq 0.05)$.

${ }^{\mathrm{b}}$ Results are expressed as mg of each tocopherol per kg of sausage as dry weight.

${ }^{\mathrm{c}}$ Results are expressed as $\mu \mathrm{mol}$ of cumene hydroperoxide equivalents per kg of sausage as dry weight.

${ }^{\mathrm{d}}$ Results are expressed as $\mu \mathrm{g}$ of malondialdehyde per kg of sausage as dry weight. 


\section{Food Science and Technology International}

${ }^{\mathrm{e}}$ Results are the area under the curve (AUC) of lipid hydroperoxide formation determined by means of the induced ferrous oxidation-xylenol orange (FOX) assay (incubation for 144 hours) and expressed as mmol of cumene hydroperoxide equivalents per kg of sausage as dry weight x hours. Only determined in freshly produced samples.

${ }^{\mathrm{f}}$ The results for acceptability are the difference between the scores for the experimental samples and the score for a commercial blind control. Only determined after storage for 60 days.

g ND, not detected. 


\section{Figure 1.}

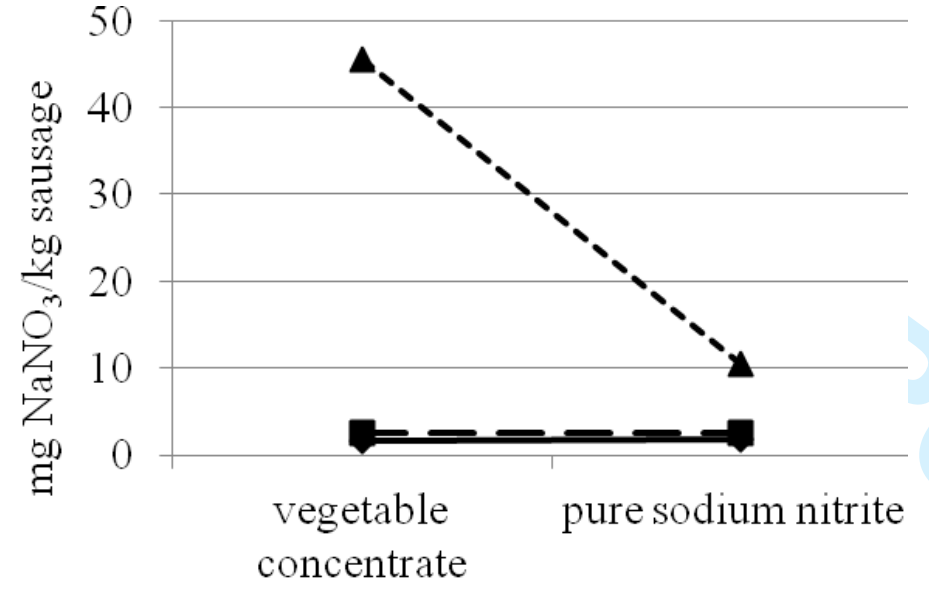

Nitrite source

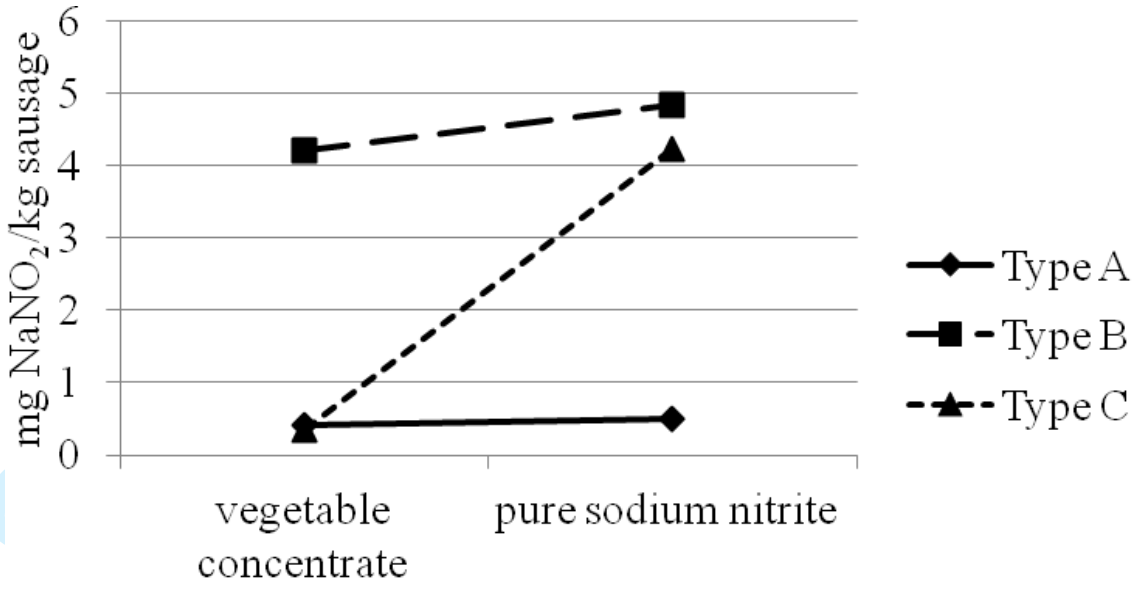

Nitrite Source

See Table 1 for description of fermentation types. 


\section{Figure 2.}

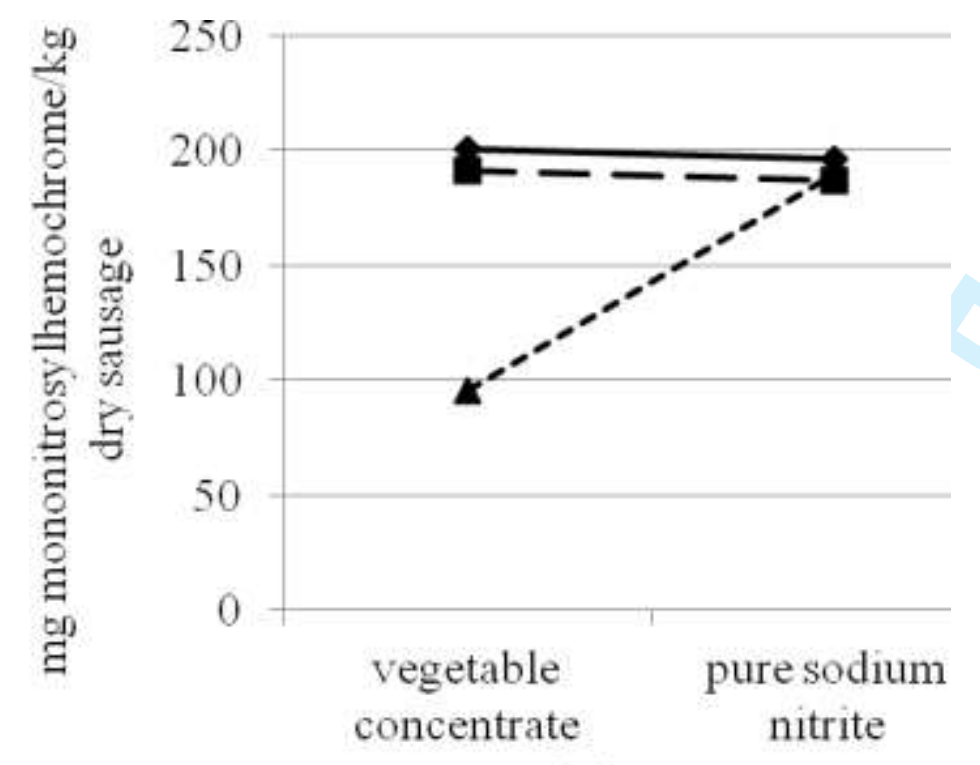

Nitrite source

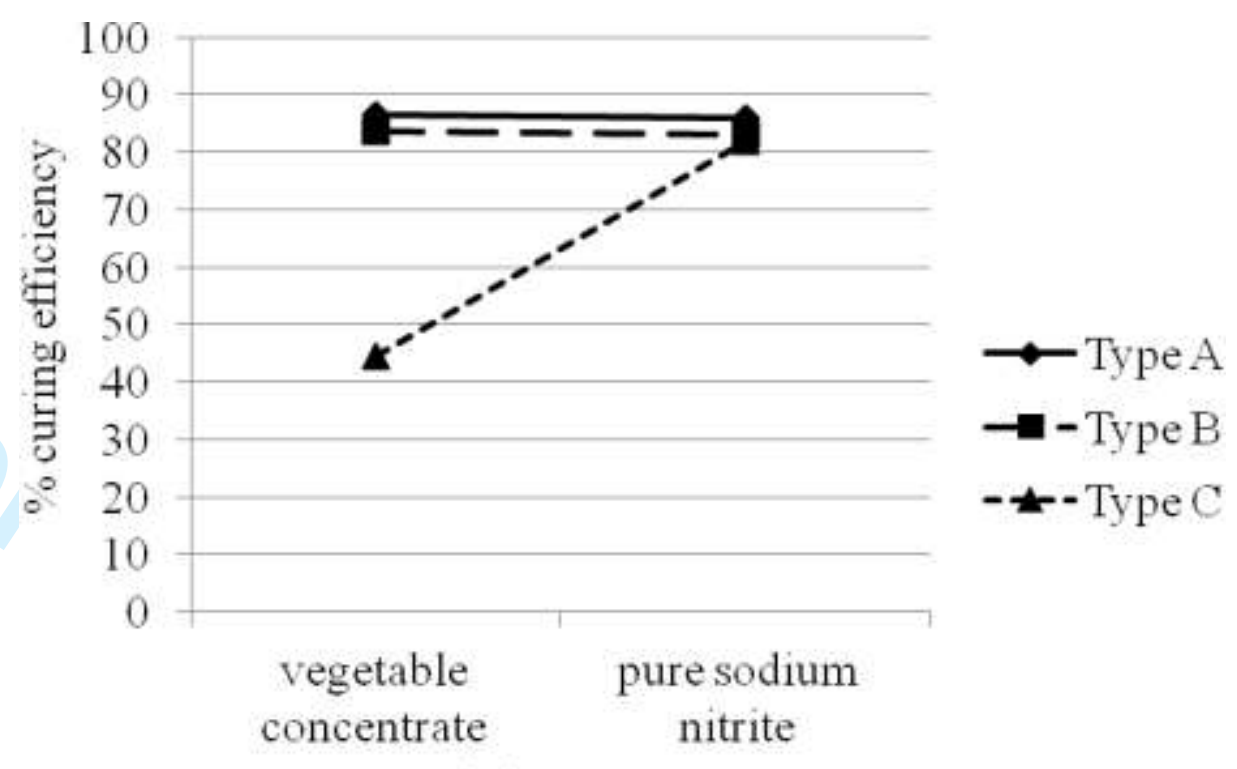

Nitrite Source

See Table 1 for description of fermentation types. 
Figure 3.

$L^{*}$

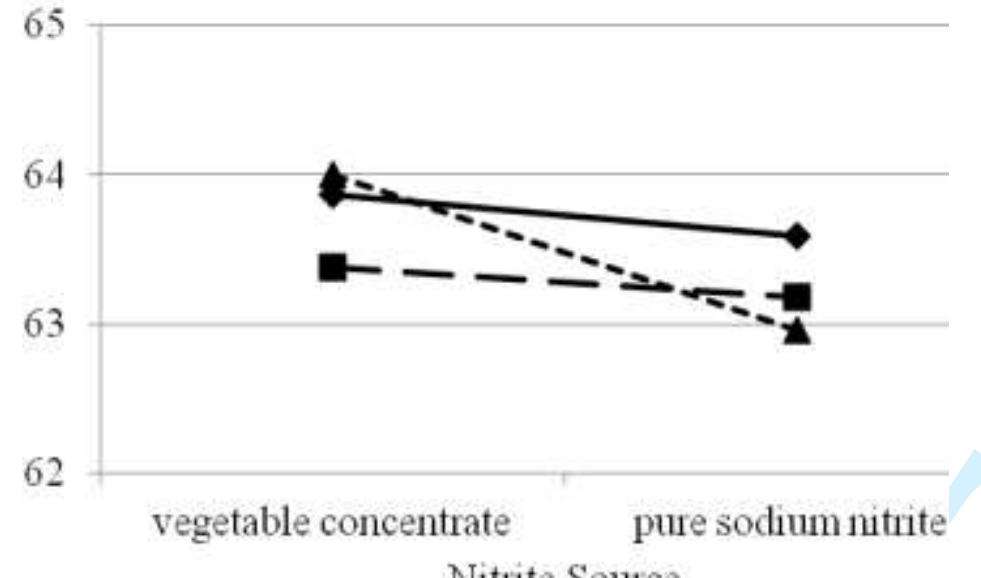

Nitrite Source

$C^{*}$

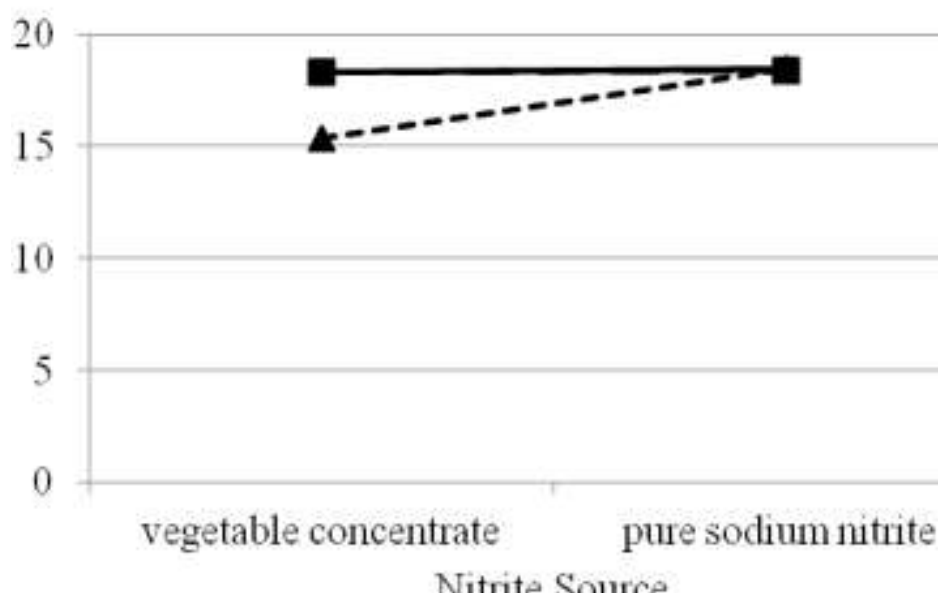

Nitrite Source

See Table 1 for description of fermentation types.

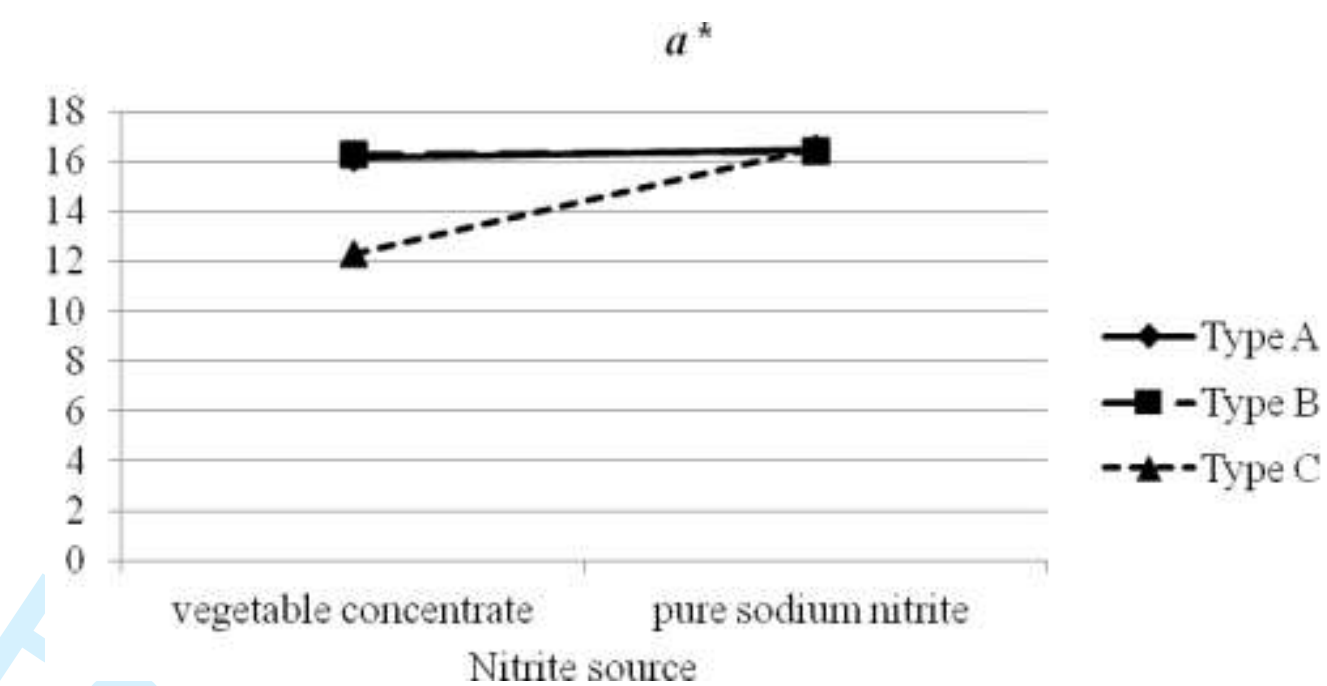

$h$

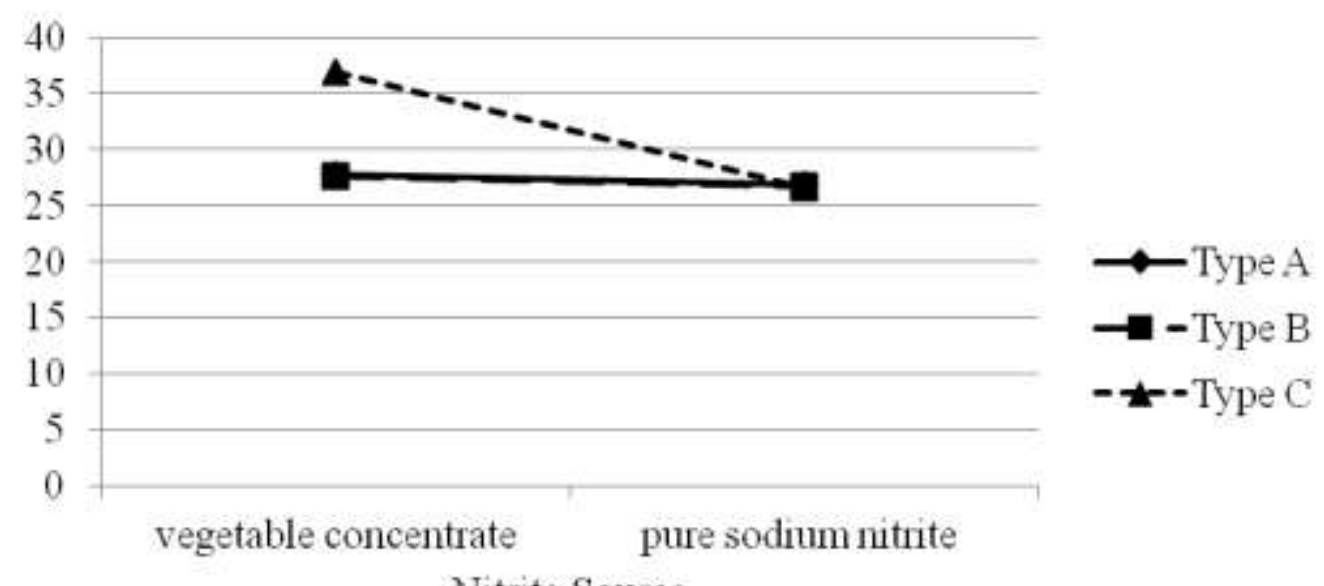

Nitrite Source 